\title{
La elaboración de diccionarios especializados para el traductor: Teoría y práctica*
}

PEDRO A. FUERTES-OLIVERA

Universidad de Valladolid

\section{INTRODUCCIÓN}

En los últimos 20 años ha aumentado el interés por la construcción de herramientas de información destinadas a ayudar a los traductores de textos especializados, por ejemplo a utilizar la terminología adecuada a la hora de traducir. Una revisión de la literatura sobre esta temática, es decir, sobre la interrelación entre lexicografía especializada (terminología/terminografía) y traducción especializada, permite extraer dos conclusiones principales.

La primera conclusión es la proliferación de nombres utilizados para referirse a la herramienta, que suele identificarse como diccionario (especializado), glosario, lexicón, enciclopedia, diccionario enciclopédico, base de datos terminológica, banco de términos, base de conocimiento terminológica, etc. (Kageura y L'Homme, 2008).

La segunda conclusión es que existen dos enfoques metodológicos diferentes relacionados con la construcción de este tipo de herramientas de referencia. Uno de los enfoques aborda esta problemática con postulados procedentes de la Lingüística (Aplicada) - principalmente de la Lingüística del Corpus, la Lingüística Cognitiva y diversos paradigmas funcionales - y la Gestión del Conocimiento (Ontologías). El otro enfoque defiende una confluencia completa entre Terminología/Terminografía y Lexicografía; este es el enfoque que seguimos en este trabajo que se traduce en la defensa de dos principios básicos que deben tenerse en cuenta a la hora de diseñar y construir diccionarios especializados.

El primero de los principios es de naturaleza teórica. Defiende que la ciencia de la lexicografía es independiente y se ocupa del desarrollo de teorías que puedan trasladarse a orientar el diseño y construcción de diccionarios prácticos y reales. Como ciencia independiente su base teórica debe centrarse en tres aspectos básicos, que constituyen el núcleo de la lexicografía: (i) las necesidades de los usuarios; (ii) la inclusión de los

* Este trabajo se inscribe en los proyectos la Teoría Funcional de la Lexicografía y la Construcción de Diccionarios en Inglés y en Español en el Campo de la Economía y la construcción de diccionarios especializados de Internet en el campo de la economía: el diccionario español de contabilidad y el diccionario español-inglés de contabilidad financiados por el Ministerio de Economía y Competitividad y la Junta de Castilla y León respectivamente (Ref. FFI2011-22885 y VA067A12-1). Agradezco a los profesores Henning Bergenholtz y Sven Tarp sus indicaciones y comentarios sobre el tema del artículo en general y de este artículo en particular.

Pedro A. Fuertes-Olivera, «La elaboración de diccionarios especializados para el traductor: Teoría y práctica», Revista de Lexicografia, XVIII (2012), pp. 7-23. ISSN: 1134-4539, e-ISSN: 2603-667. DOI: https://doi.org/10.17979/rlex.2012.18.0.3767 
datos lexicográficamente relevantes, es decir pensados para solucionar las necesidades de los usuarios; (iii) la puesta a disposición del usuario de rutas de acceso a los datos que sean fáciles de manejar y comprender. El segundo de los principios es de naturaleza práctica: el diseño y elaboración de diccionarios debe tener en cuenta también el análisis de los costes lexicográficos (Bergenholtz y Tarp, 1995, 2002, 2003, 2004, 2005; Fuertes-Olivera, 2012a y 2012b; Fuertes-Olivera y Nielsen, 2011 y 2012; Fuertes-Olivera y Tarp, 2008, 2011; Nielsen, 2008; Tarp, 2008 y 2012a y b). Ambos principios están conectados con aspectos universales presentes en todas las épocas de la historia y aspectos específicos propios de las opciones tecnológicas con las que contamos en cada momento de la historia.

La llegada y generalización de Internet es una característica propia de nuestra época y como tal debe tenerse en cuenta y comprender su influencia. Hay en estos momentos tres líneas de investigación diferentes ocupadas en analizar la influencia de Internet en el diseño y construcción de materiales de referencia: (1) la extracción (semi-) automática de términos con el objetivo de construir artículos terminológicos de forma (semi-) automática (Heid y Gojun, 2012); (ii) la construcción de bases de conocimiento terminológicas, ontologías, y otros sistemas expertos (Valaski, Malucelli y Reinehr, 2012); (iii) la construcción de diccionarios especializados de Internet pensados para favorecer la individualización y reutilización de los datos con vistas a elaborar diccionarios con artículos dinámicos y datos dinámicos (Fuertes-Olivera y Bergenholtz, 2011).

En el marco que acabamos de señalar este trabajo se sitúa en la línea de investigación relacionada con el diseño y construcción de diccionarios de Internet. Defiende el empleo del nombre diccionario especializado (Sección 2) y su diseño y elaboración de acuerdo con la teoría funcional de la lexicografía (Sección 3). Además aborda el uso de las tecnologías de Internet con el objetivo de diseñar herramientas que favorezcan la individualización y la preparación de diccionarios de Internet que cuenten con artículos dinámicos y datos dinámicos adaptados a las necesidades específicas de los traductores. La propuesta la ilustramos con dos diccionarios de Internet que pueden consultarse en Lemma.com (Figura 1) (Sección 4): Diccionario Inglés-Español de Contabilidad: Traducción (Fuertes-Olivera et al., 2012a) y Diccionario Inglés-Español de Contabilidad: Traducción de Frases y Expresiones (Fuertes-Olivera, 2012b). El trabajo finaliza resumiendo las principales conclusiones alcanzadas en el artículo.

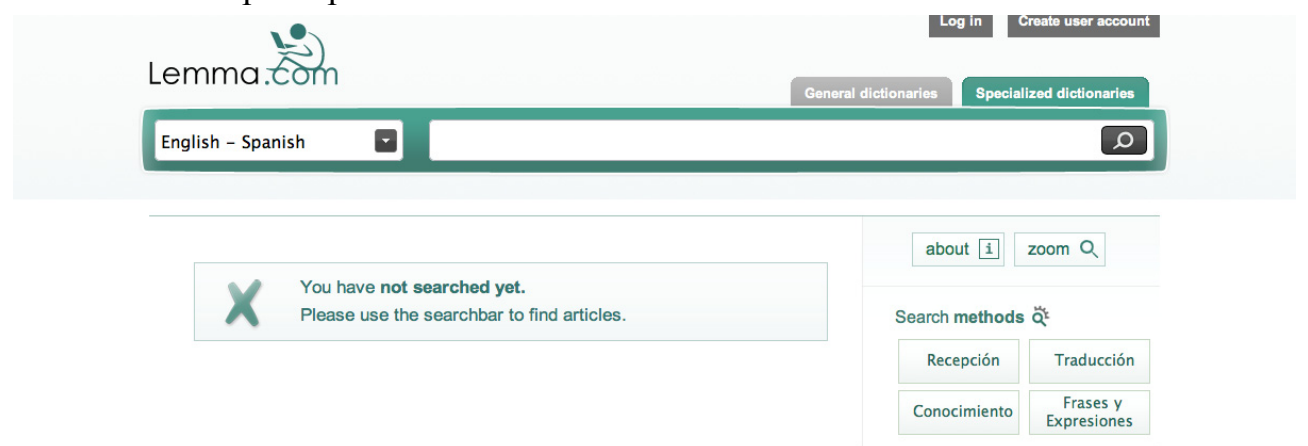

Figura 1: Captura de pantalla del Diccionario Inglés-Español de Contabilidad 


\section{EL CONCEPTO DE DICCIONARIO ESPECIALIZADO}

En la mayoría de los dominios de especialidad nos encontramos con nombres diversos para referirse a una herramienta de información que almacena los términos utilizados en esa especialidad. Son frecuentes los nombres siguientes: tesauro, taxonomía, clasificación, glosario, ontología, vocabulario controlado, enciclopedia, diccionario enciclopédico, diccionario especializado, base de datos terminológica y banco de conocimiento terminológico. Creemos que esta proliferación de nombres solo ayuda a aumentar la confusión sobre la naturaleza de las mismas como herramientas de información. Por ejemplo, en Genoma, que se describe como un banco de conocimiento terminológico, un traductor de textos de inglés a español accede a definiciones de los conceptos que muestran diferencias importantes entre las mismas, aunque sus editores afirman la importancia del empleo de redes y mapas conceptuales en su elaboración (Feliu et al., 2002). El ejemplo (1) muestra la definición de «DNA» en inglés y español recogida en Genoma:

Definició: The molecule that encodes genetic information. DNA is a doublestranded molecule held together by weak bonds between base pairs of nucleotides. The four nucleotides in DNA contain the bases adenine (A), guanine $(\mathrm{G})$, cytosine $(\mathrm{C})$, and thymine $(\mathrm{T})$. In nature, base pairs form only between $\mathrm{A}$ and $\mathrm{T}$ and between $\mathrm{G}$ and $\mathrm{C}$; thus the base sequence of each single strand can be deduced from that of its partner.

Definició: Abreviatura de ácido desoxirribonucleico (en inglés deoxyribonucleic acid o DNA). Es la molécula que contiene y transmite la información genética de los organismos excepto en algunos tipos de virus (retrovirus). Está formada por dos cadenas complementarias de nucleótidos que se enrollan entre sí formando una doble hélice que se mantiene unida por enlaces de hidrógeno entre bases complementarias. Los cuatro nucleótidos que forman el ADN contienen las bases adenina (A), guanina (G), citosina (C) y timina (T). Dado que en el ADN la adenina se empareja sólo con la timina y la citosina sólo con la guanina, cada cadena del ADN puede ser empleada como molde para fabricar su complementaria.

Ejemplo 1: Definición de DNA en inglés y español en Genoma

Las diferencias entre ambas definiciones afectan tanto a aspectos formales y secundarios (por ejemplo, en español se afirma que DNA es una abreviatura de deoxyribonucleic acid y en inglés no aparece este dato), como a aspectos centrales de su significado, especialmente los siguientes:

- DNA tiene forma de doble hélice: esta información aparece en español pero no en inglés.

- La doble hélice está unida por enlaces de hidrógeno entre bases complementarias: esta información aparece en español pero no en inglés.

- El DNA puede usarse como un molde para producir su molécula complementaria: esta información está en español pero no en inglés. 
- El DNA transmite la información genética, excepto en algunos tipos de virus (los retrovirus): esta información no aparece en inglés, aunque es realmente importante y fundamental.

Siguiendo con nuestra argumentación, la definición recogida en Genoma no es diferente de la que tiene IATE, que se define como base de datos terminológica (ejemplos 2 y 3). Incluso la definición de Genoma es mucho menos completa que la que puede encontrase en Wikipedia o en el Gene Technology Encyclopedic Dictionary, que se definen como enciclopedia y diccionario enciclopédico respectivamente. Por ejemplo, la definición de DNA en el Gene Technology Encyclopedic Dictionary (Kaufmann et al., 1998) tiene más de 1000 palabras que precisan el concepto de varias formas (es decir, para diferentes tipos de usuarios potenciales) y lo complementan indicando su estructura, función y otras informaciones importantes, como los párrafos explicativos de los «genomas procariotas» y los «genomas eucariotas».

DNA 1.The basic unit of DNA is the nucleotide (containing one of four bases). A DNA strand can be made up of thousands of nucleotides joined by a backbone of phosphate sugars. Chromosomes typically are constructed of two strands of DNA twisted together in the shape of a double helix. Specific nucleotide sequences define genes, which encode instructions for cell function and products (including proteins). The human genome contains 100,000 genes, or $3 \times 109$ base pairs; the simplest bacterium contains about 2,000 genes, or 2 million base pairs.

Ejemplo 2: Definición de DNA en IATE (Industria Farmacéutica)

DNA 1.The principal material of inheritance. It is found in chromosomes and consists of molecules that are long unbranched chains made up of many nucleotides. Each nucleotide is a combination of phosphoric acid, the monosaccharide deoxyribose and one of four nitrogenous bases: thymine, cytosine, adenine or guanine. The number of possible arrangements of nucleotides along the DNA chain is immense. Usually two DNA strands are linked together in parallel by specific base-pairing and are helically coiled. Replication of DNA molecules is accomplished by separation of the two strands, followed by the building up of matching strands by means of basepairing, using the two halves as templates. By a mechanism involving RNA, the structure of DNA is translated into the structure of proteins during their synthesis from amino acids.

Ejemplo 3: Definición de DNA en IATE (Medio ambiente)

Los ejemplos (1), (2) y (3) no tienen la intención de criticar la calidad de cada una de las herramientas de información, sino de argumentar la necesidad que tenemos en este campo de utilizar nombres que faciliten la labor de identificación del usuario de los mismos. Es con este propósito con el que los partidarios de la teoría funcional de la lexicografía inicialmente desarrollada en la Universidad de Aarhus a partir de la década de 1990, utilizamos el término diccionario especializado como término genérico adecuado para identificar cualquier material de referencia que trate temas fuera del alcance de la cultura general y sus lenguas y se construya y diseñe para ofrecer acceso 
directo al mismo con el fin de satisfacer las necesidades puntuales que un usuario potencial pueda tener en una situación de uso concreta, por ejemplo cuando quiere conocer algo (situación cognitiva) o cuando quiere leer, escribir o traducir algo (situación comunicativa) (Tarp, 2012a).

\section{LA TEORÍA FUNCIONAL DE LA LEXICOGRAFÍA Y LA LEXICOGRAFÍA DE INTERNET}

La Teoría Funcional de la Lexicografía o teoría de las funciones es una construcción teórica iniciada en la década de 1990 en el Centre for Lexicography de la Universidad de Aarhus. Presenta la ciencia de la lexicografía como independiente y centrada en el desarrollo de teorías que puedan trasladarse a orientar el diseño y construcción de diccionarios prácticos y reales. Deben ser diccionarios que puedan satisfacer las necesidades de un tipo específico de usuario con problemas específicos que se presentan en una situación de uso específica. En este marco la teoría funcional cambia el foco de atención de los usuarios reales del diccionario a los diccionarios potenciales del mismo y a la situación social en la que se encuentran.

Desde sus inicios, la teoría funcional ha ido construyendo un cuerpo doctrinal con su correspondiente aplicación práctica en el que han participado sus iniciadores (Bergenholtz y Tarp, 2002, 2003, 2004; Tarp, 2008), sus colaboradores - por ejemplo, Almind (2005), Nielsen, (2008), Leroyer (2011) - y un buen número de profesores de varios países y continentes que han visto en la misma una metodología adecuada para llevar a buen puerto actividades académicas que van desde la meta-lexicografía a la construcción real de diccionarios, e. g. Bergenholtz y Gouws, 2010; Bergenholtz, Bothma y Gouws, 2011; Bergenholtz y Bothma, 2011; Fata, 2010; Fuertes-Olivera 2009a, 2009b, 2011, 2012a y 2012b ; Fuertes-Olivera y Nielsen 2011 y 2012; FuertesOlivera y Tarp, 2011; Kwary, 2011 y 2012; Xue, 2010 y 2011. Todo este trabajo se ha traducido en una visión de la lexicografía que combina tres elementos centrales: (1) un planteamiento teórico centrado en la naturaleza de la lexicografía; (2) la aplicación práctica de la teoría; (3) la apertura de miras con el fin de incorporar cualquier aportación que pudiera hacerse procedente de otros campos, por ejemplo las Ciencias de la Información, para el desarrollo de la e-lexicografía o lexicografía de Internet.

La teoría funcional defiende que la naturaleza de la lexicografía está en la presencia de tres elementos centrales que configuran cualquier herramienta de información: (1) los datos que debe contener; (2) las necesidades de los usuarios; y (3) las rutas de acceso. Esto hace que sus formulaciones teóricas sean válidas para todas las herramientas de información al nivel de abstracción más elevado posible, es decir cuando no nos centramos en un tipo concreto de datos, de usuarios, o de rutas de acceso específicas (Tarp, 2012b). Es en este nivel de abstracción más elevado posible en el que se encuentra la información fundamental que se investiga principalmente de una manera deductiva, es decir, imaginando la situación potencial de uso, las características del usuario y sus necesidades y la mejor forma posible que tengamos para lograr que quede satisfecho de la consulta realizada, no solo porque ese usuario ha sido capaz de encontrar lo que buscaba sino también porque ese proceso fue rápido y poco costoso. 
Además, las necesidades de información de los usuarios nunca son necesidades abstractas en el plano lexicográfico sino que siempre se ven como necesidades íntimamente relacionadas con usuarios potenciales en situaciones de uso potenciales, como por ejemplo un usuario potencial en una situación de recepción de un texto especializado necesita solamente datos que le permitan conocer el significado de la palabra o expresión que está buscando. Por consiguiente, las necesidades del usuario en términos lexicográficos se tratan siempre como tipos específicos de necesidades de información relacionadas con tipos específicos de usuarios que se encuentran en tipos específicos de situaciones sociales extra-lexicográficas.

Igualmente, la teoría funcional intenta encontrar fórmulas de acceso a los datos que sean rápidas y eficaces con la esperanza de que el usuario transforme esos datos en la información que necesita. Por ejemplo, los datos que necesita un estudiante de un curso de inglés especializado depende de varios factores como pueden ser su nivel de dominio de la especialidad y de la lengua, y el lugar físico en el que está intentando dominar esa lengua. Es por ello que en las formulaciones más recientes de la teoría funcional estén empezando a cobrar protagonismos dos elementos extra-lexicográficos que tienen una gran importancia en la era de Internet: los costes lexicográficos (Nielsen, 2008) y el uso de la tecnología de Internet para hacer diccionarios, consultar diccionarios y actualizar diccionarios (Bothma, 2011; Bergenholtz, 2011; Fuertes-Olivera, 2012a; Gouws, 2011; Nielsen y Almind 2011; Tarp, 2011).

En el marco de la Teoría Funcional de la Lexicografía, los diccionarios especializados de Internet se conciben y proyectan como un trabajo colaborativo en el que normalmente participan cuatro tipos de expertos, cada uno de los cuales aporta sus conocimientos sobre la herramienta de uso (normalmente la misión del lexicógrafo), sobre Internet como tecnología (normalmente un experto en Ciencias de la Información), sobre el tema del diccionario (por ejemplo un experto en ciclismo si el diccionario es sobre el ciclismo), y sobre su venta y distribución.

Todos estos elementos han dado sus frutos en el diseño de un conjunto de diccionarios especializados que son ejemplo de Modelo T Ford, nombre con el que Tarp (2011) identifica al diccionario que utiliza las tecnologías de Internet para ofrecer soluciones monofuncionales, es decir datos presentes en artículos dinámicos con datos dinámicos. Algunos de estos diccionarios se ocupan del lenguaje de la contabilidad y entre ellos se encuentran dos diccionarios diseñados para satisfacer las necesidades de los traductores especializados: el Diccionario Inglés-Español de Contabilidad: Traducción (FuertesOlivera et al., 2012a) y el Diccionario Inglés-Español de Contabilidad: Traducción de Frases y Expresiones (Fuertes-Olivera et al., 2012b).

\section{EL DICCIONARIO INGLÉS-ESPAÑOL DE CONTABILIDAD: TRADUCCIÓN Y EL DICCIONARIO INGLÉS-ESPAÑOL DE CONTABILIDAD: TRADUCCIÓN DE FRASES Y EXPRESIONES}

El enfoque que defendemos en el marco de la teoría funcional de la lexicografía nos ha llevado a construir el Diccionario de Contabilidad pensando en las funciones que debe tener para satisfacer las necesidades de tres tipos preferentes de usuarios con ne- 
cesidades comunicativas y cognitivas en el campo de la contabilidad en danés, español e inglés. La confección de este diccionario ha tenido dos consecuencias importantes.

La primera de ellas es la puesta en práctica de una herramienta de información especializada que adopta una orientación transformativa de la lexicografía (Tarp, 2002). Esto quiere decir que los conceptos lexicográficos se van adaptando continuamente a las necesidades detectadas en los usuarios de los diccionarios; necesidades que conocemos gracias a la información que suministran los mismos usuarios, es decir feedback activo, la que conocemos analizando los ficheros que registran las búsquedas de los usuarios (log files o feedback pasivo), y la que procede de la actividad académica llevada a cabo con este conjunto de diccionarios especializados, que se ha traducido en cerca de 30 publicaciones, muchas de ellas en revistas y colecciones internacionales (ver Bergenholtz, 2012; Fuertes-Olivera, 2009a, 2011; Fuertes-Olivera y Nielsen, 2011 y 2012; Fuertes-Olivera y Tarp, 2011; Nielsen y Almind, 2011; Tarp, 2012a).

La segunda consecuencia es el desarrollo y puesta en práctica de ideas que son una novedad completa para el español, tanto para el español general como para el especializado. Entre estas ideas mencionamos las siguientes:

1. La construcción del diccionario se aborda como un proceso de construcción continua. Esto quiere decir que la base de datos lexicográfica está en un proceso continuo de incorporación de nuevas fichas, de adaptaciones, correcciones, modificaciones, etc. Al mismo tiempo, se va modificando el diccionario que consulta el usuario, normalmente mejorando los programas de búsqueda, filtrado, recuperación de artículos, cambiando el diseño de la página, por ejemplo el tipo de letra y creando conceptos lexicográficos nuevos si son necesarios y lo permiten las innovaciones tecnológicas. Por ejemplo, el Diccionario inglés-español de contabilidad: traducción de frases y expresiones surge gracias al desarrollo de nuevos conceptos lexicográficos, como veremos más adelante.

2. El diccionario se comercializa como un producto típico de la economía basada en el conocimiento: es un producto realizado en universidades que está destinado al consumo de usuarios, principalmente traductores, que pagan una suscripción para poder utilizarlo. Esto quiere decir que en el desarrollo de este producto también intervienen empresas que saben convertir los conceptos lexicográficos en bases de datos lexicográficas, que disponen de la tecnología necesaria para diferenciar la base de datos del diccionario, y que saben vender el diccionario a través de Internet.

3. El diccionario se enfrenta a lo que se llama el efecto Google, es decir a búsquedas que ofrecen cantidades ingentes de datos desestructurados. Ofrece como solución motores de búsqueda y resultados de búsqueda diferenciados, que nos han permitido afirmar que existe una base de datos y 27 diccionarios, cada uno de los cuales ofrece nada más (ni nada menos) que los datos que creemos necesarios para el usuario que se encuentra en una situación concreta, como el Diccionario Inglés-Español de Contabilidad: Traducción y el Diccionario Inglés-Español de Contabilidad: Traducción de Frases y Expresiones. 
Los dos diccionarios que acabamos de mencionar son diccionarios construidos para solucionar las necesidades específicas de los traductores de textos de contabilidad. Esto es posible porque los autores de los diccionarios diferencian, tanto a nivel ontológico como a nivel práctico, entre la base de datos lexicográfica, que debe contener el mayor número de datos lexicográficamente relevantes posible, y el diccionario, que solo debe contener el número de datos adecuados a la situación de uso en la que se encuentra el diccionario (Bergenholtz, 2011). Esta es la idea básica que subyace a nuestra visión de la individualización de los datos que el uso adecuado de la tecnología de Internet permite. Por ejemplo, la base de datos lexicográfica contiene un espacio para almacenar definiciones, equivalentes, información de uso, datos gramaticales, etc. (Figura 2).

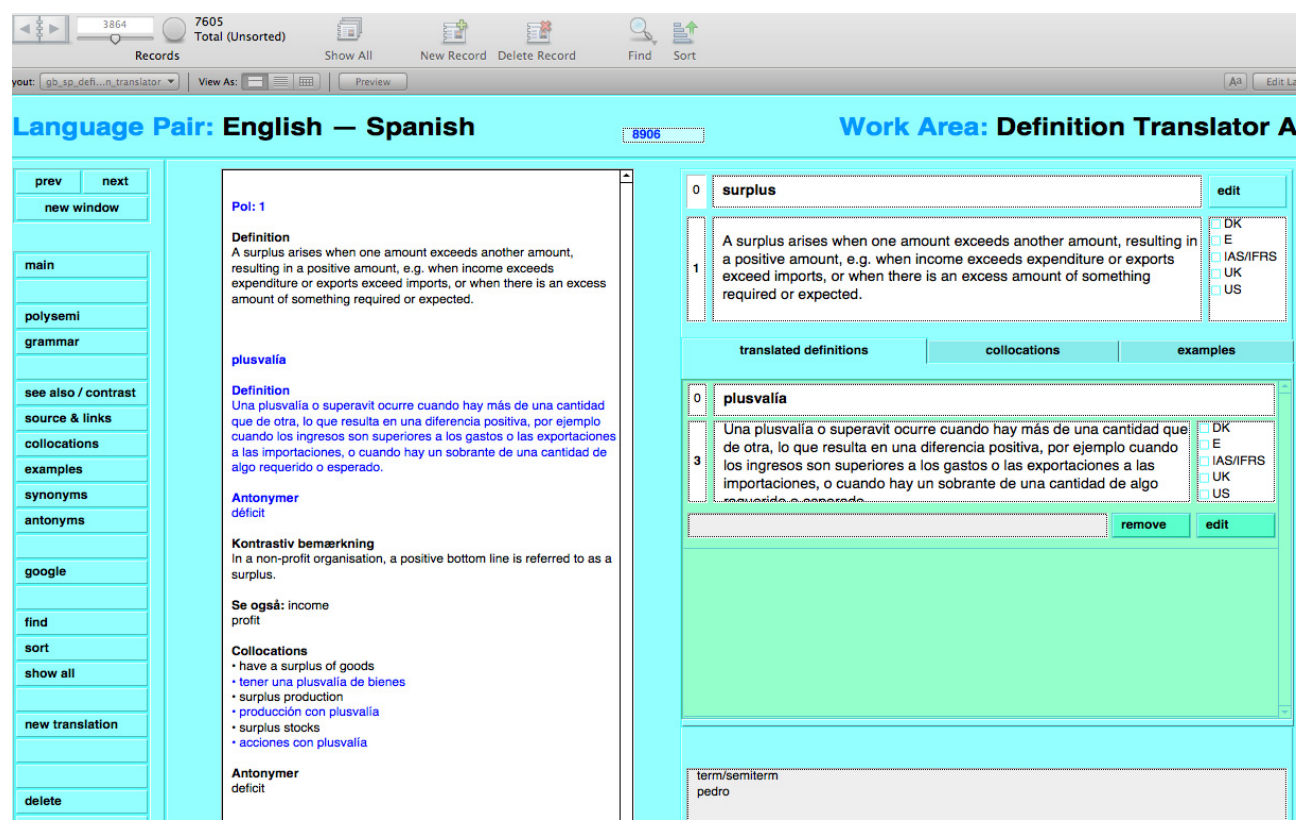

Figura 2. La entrada surplus en la base de datos lexicográfica del Diccionario InglésEspañol de Contabilidad

La figura 2 es uno de los formatos de la base de datos que utiliza el lexicógrafo para construir el artículo del diccionario (hay otros formatos para el inglés, español, danés, español-inglés, danés-inglés e inglés-danés). El formato de la Figura 2 corresponde al Inglés-Español e incluye lo siguiente:

1. Lema (término) en inglés.

2. Índice de homonimia (si es necesario). Es un superíndice que indica que dos o varios homógrafos pertenecen a dos categorías gramaticales diferentes o pertenecen a la misma categoría gramatical, pero con flexiones diferentes. Por ejemplo, account puede ser un nombre contable, un verbo, y un nombre no contable, por lo que va precedido de los números 1,2 , y 3 para indicar 
este hecho, que corresponden a los equivalentes españoles cuenta, poner en libros y consideración, respectivamente.

3. Índice de polisemia (si es necesario). Es un número arábigo que indica que un homógrafo perteneciente a la misma categoría gramatical tiene varios significados o conceptos. Por ejemplo el nombre contable cuenta va con los índices 1, 2, y 3 para indicar que tiene tres significados: una cuenta es un sistema de representación de elementos patrimoniales (ej. Las cuentas del activo); una cuenta es un acuerdo entre empresas o individuos para acceder a una especie de crédito (ej. Tener una cuenta en el Corte Inglés); y una cuenta es un depósito en un banco (ej. Tener una cuenta en el Santander).

4. Código describiendo la variante lingüística del lema (si es necesario), como por ejemplo que el término es español IAS/IFRS, es decir, es un término español que entró al redactar las Normas Internacionales de Contabilidad y puede convivir con el término tradicional español (ej. la operación interrumpida es un término IAS/IFRS que convive con el término español operación discontinua).

5. Flexión: contiene los datos gramaticales que se refieren al lema. Por ejemplo, para los verbos españoles presentamos cuatro formas activas - tercera persona del presente y pretérito, el participio y el gerundio - y cuatro formas pasivas, la tercera persona singular del presente y pretérito de la voz pasiva refleja, el participio pasivo y gerundio pasivo. Por ejemplo para $d i$ vulgar tenemos divulga, divulgó, divulgado, divulgando, se divulga, se divulgó, sido divulgado y siendo divulgado.

6. Equivalente español.

7. Definición del lema. Las definiciones van en inglés y en español. Este hecho responde a una necesidad detectada entre usuarios españoles con un manejo del inglés un poco deficiente.

8. Colocaciones en inglés y sus traducciones al español.

9. Código lingüístico de las colocaciones (si existe), por ejemplo para indicar que es una colocación sacada de un texto IAS/IFRS.

10. Ejemplos en inglés y su traducción al español.

11. Sinónimos.

12. Antónimos.

13. Códigos lingüísticos de los sinónimos y antónimos (si existen); por ejemplo el código IAS/IFRS para un sinónimo extraído de una Norma Internacional de Contabilidad.

14. Fuente (si existe): es un hipervínculo a un texto externo accesible a través de Internet. Siempre es un texto fiable, por ejemplo, la página web encargada de desarrollar las Normas Internacionales de Contabilidad.

15. Notas gramaticales sobre el lema o equivalente (si son necesarias). Por ejemplo, para indicar que el plural de déficit puede ser déficit o déficits.

16. Notas contrastivas (donde sean necesarios). Por ejemplo, para indicar el nombre del regulador contable en varios países.

17. Notas de uso (donde sean necesarios). Por ejemplo, una nota para indicar que las acciones españolas tienen los mismos derechos de voto, algo que no ocurre, por ejemplo, en el Reino Unido.

18. Hipervínculos con referencias cruzadas a otros elementos del diccionario. 
19. Indicador proscriptivo: es una marca para indicar al usuario cuál de las posibles variantes consideramos más adecuada. Por ejemplo, es un indicador adecuado para indicar que los lexicógrafos consideramos que es mejor utilizar amortización degresiva que amortización decreciente.

El usuario no tiene acceso a esos datos; solo tiene acceso a los datos que los lexicógrafos consideramos adecuados a la situación de uso. Estos datos van precedidos de códigos de comunicación interno que reciben los expertos en bases de datos de Internet que trabajan en el proyecto, que han diseñado, además, sistemas de búsquedas minimizadoras que facilitan la recuperación de la información adecuada a la situación de uso descrita por el usuario (Bergenholtz, 2011). Este sistema de trabajo permite al usuario acceder a datos dinámicos, es decir, a datos pensados para satisfacer su consulta puntual ofreciéndole solo lo que necesita y nada más de lo que necesita. Por ejemplo, si un usuario busca accounts en el Diccionario Inglés-Español de Contabilidad: Traducción recupera lo siguiente:

1. indicador geográfico (término utilizado en el Reino Unido);

2. indicador gramatical (nombre);

3. la definición en español e inglés del término;

4. el equivalente español cuentas anuales;

5. parte de la oración, género y restricciones de uso por razones gramaticales del equivalente (es un nombre femenino plural, que puede ir con artículo definido e indefinido);

6. el sinónimo estados financieros en forma de hipervínculo;

7. 13 colocaciones en inglés traducidas al español;

8. 1 ejemplo inglés traducido al español. (Figura 3) 

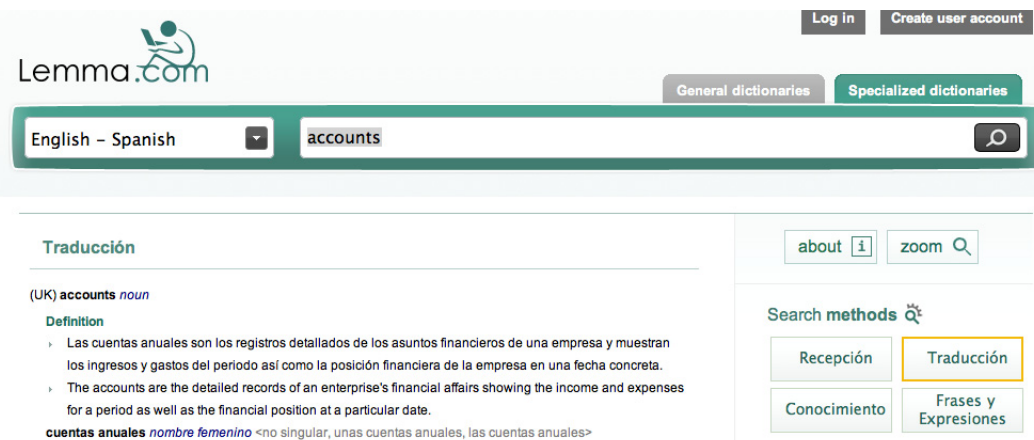

bre temenino <no singular, unas cuentas anuales, las cuentas anuales

Collocations

audit the accounts (UK)

auditar las cuentas anuales

users of accounts (UK)
usuarios de las cuentas an

preparers of accounts (UK)

preparadores de las cuentas anuales

annual accounts (UK)

cuentas anuales

cuentas anuales consolidaa

prepare accounts (UK)

preparar las cuentas anual

close the accounts (UK)

cerrar las cuentas anuales
balance the accounts (UK)

las cuentas de balance

keep accounts (UK)

registrar las cuentas anuales

report and accounts (UK)

informe y cuentas anuales

audited accounts (UK)

cuentas anuales auditadas
present the accounts (UK)

presentar las cuentas anuales

the reliability of the accounts (UK)

, Ia fabilitiog

These accounts were approved by the Board of Directors on 8 March 2006. (UK)

El Consejo de Administración aprobo estas cuentas anuales el 8 de marzo de 2006.

Figura 3. Pantalla de accounts en el Diccionario Inglés-Español de Contabilidad: Traducción

Los datos que recibe el usuario al consultar este diccionario son los datos que normalmente se comentan en la literatura científica relacionada con las necesidades de los traductores de textos especializados (Fuertes-Olivera y Nielsen, 2012; Tarp, 2008). Estos usuarios necesitan un sistema de desambiguación del significado claro y fácil de entender, por ejemplo las definiciones en las dos lenguas y los indicadores de homonimia y polisemia, si fueran necesarios. Estos traductores también necesitan un único equivalente, de forma que puedan hacer un uso sistemático de la terminología en la lengua de llegada. Necesitan, además, contextos en los que aparezca contextualizado el término y una traducción del contexto que nosotros ofrecemos traduciendo las colocaciones y ejemplos. Además, en un registro especializado necesitan conocer la clase gramatical y la flexión en la lengua de llegada, es decir saber por ejemplo si el nombre 
es contable, incontable, masculino, femenino, etc. Por ejemplo, en contabilidad hay más de 10 términos españoles con método que solo aparecen en singular y precedidos por un artículo definido, como el método de la deuda basado en el balance (balancesheet liability method en inglés), que tiene esta restricción de uso porque este método es un método muy específico que «implica que el pasivo fiscal y el gasto fiscal se calculan en base a las diferencias existentes entre el valor contable de un activo o pasivo en el balance y su base fiscal (diferencias temporarias)» (definición en el diccionario).

Nuestra investigación sobre las necesidades reales de los usuarios, especialmente las derivadas de la consulta de los log files y la interpretación de los correos electrónicos de traductores profesionales nos hizo ver que los traductores profesionales también tienen otra necesidad, especialmente en caso de usuarios con mucha experiencia como traductores especializados pero con poca experiencia en un campo concreto del saber. Descubrimos que este tipo de traductores necesitan todos los contextos posibles en los que pueda usarse el término que buscan ya que saben por experiencia de las diversas posibilidades significativas, gramaticales, o discursivas que éstos tienen y de la existencia real de polisemias y homonimias que dificultan la comprensión del significado del término. Hemos hecho frente a esta necesidad creando el Diccionario Inglés-Español de Contabilidad: Traducción de Frases y Expresiones. Este diccionario tiene unas 30.000 expresiones de contabilidad y el usuario recupera todas las que contienen el término que busca. Por ejemplo, si busca accounts en este diccionario recupera 23 expresiones, cada una de las cuales tiene acceso a la entrada o entradas correspondiente(s) en el diccionario (Figura 4).

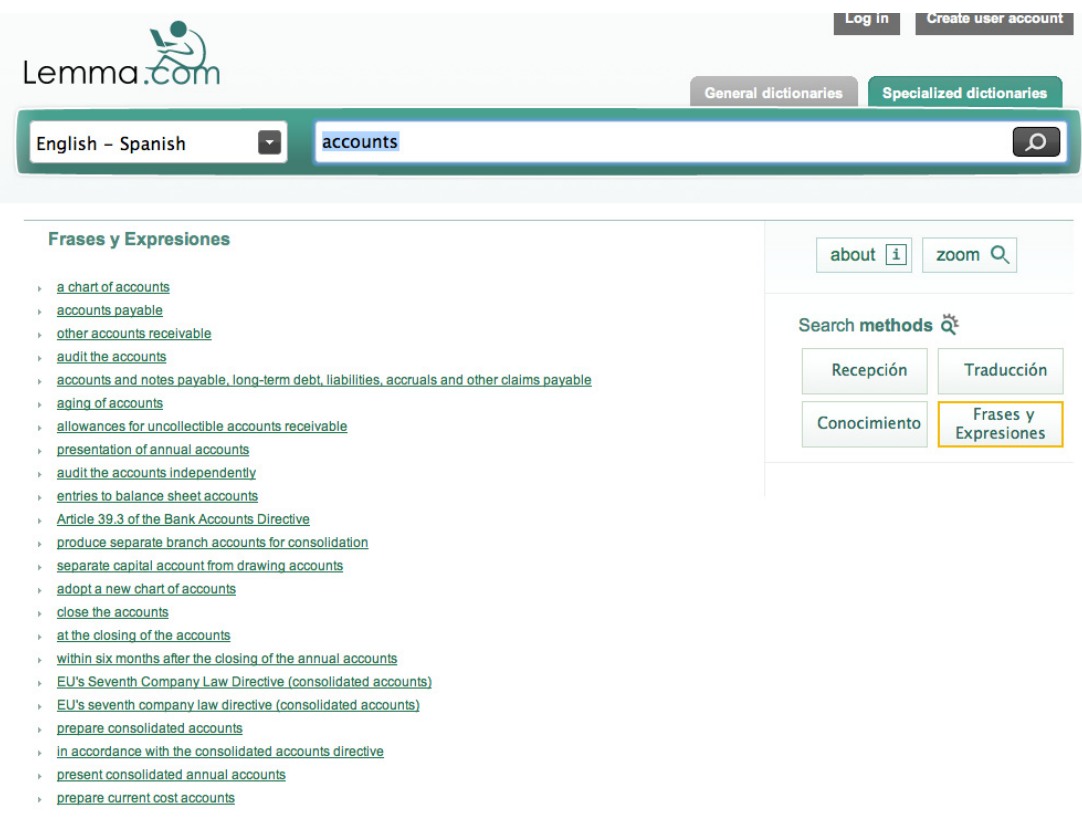

Figura 4. Pantalla de accounts en el Diccionario Inglés-Español de Contabilidad: Traducción de Frases y Expresiones 
Situándose encima de cada una de la frases y expresiones y haciendo «click» con el ratón, el usuario accede a la expresión en todas las entradas del diccionario en la que dicha expresión se encuentra. Por ejemplo, en EU's Seventh Company Law Directive (consolidated accounts) recupera las entradas del diccionario para Company Law Directive (nombre propio) y company law directive, que es un nombre común. Este hecho informa al usuario de la existencia de variantes que pueden serle útiles en el quehacer cotidiano del traductor profesional para el que el tiempo es oro. Por este motivo el diccionario resalta el término buscado y hace que la búsqueda sea muy rápida y fácil de visualizar (Figura 5).

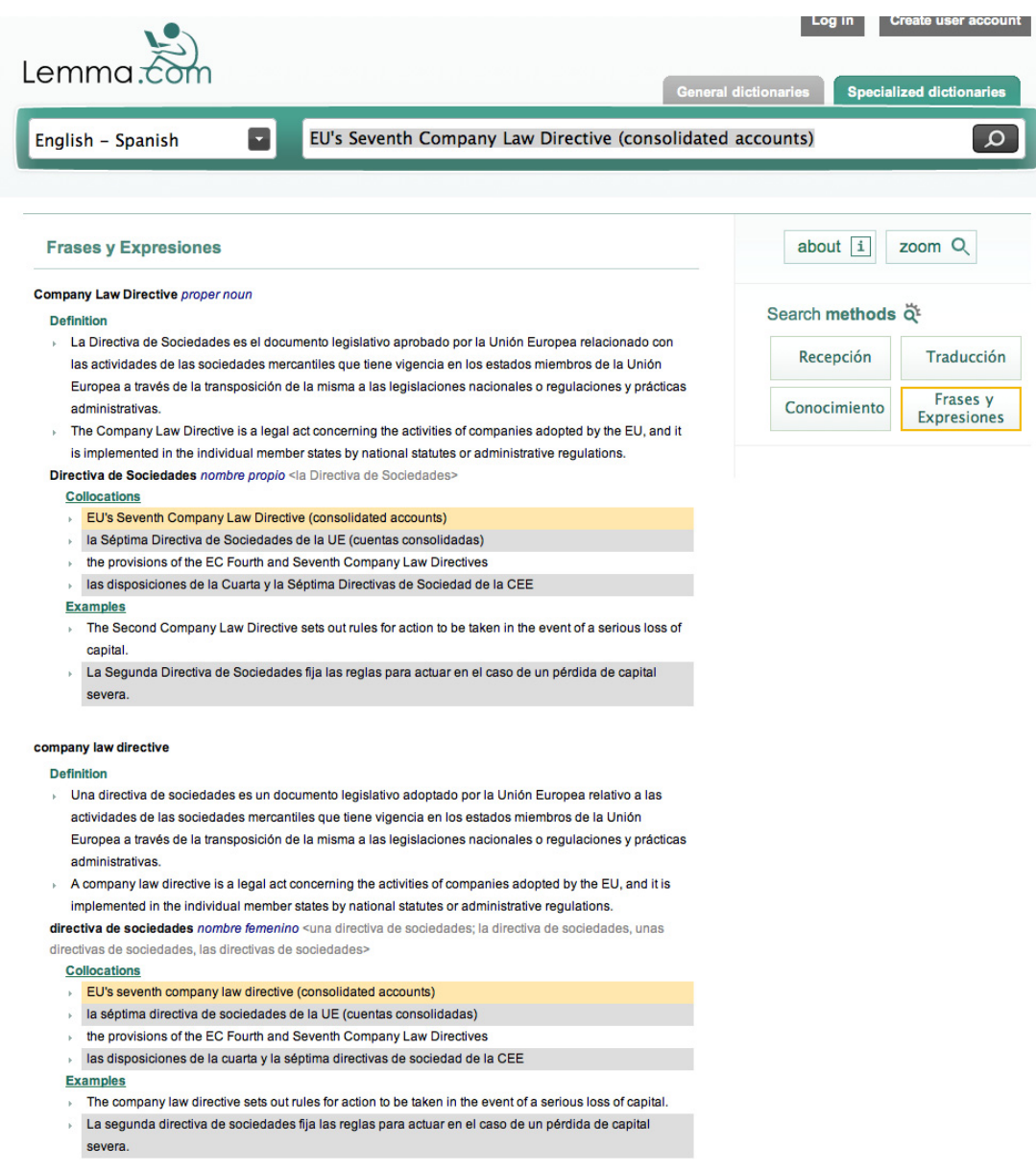

Figura 5. EU's Seventh Company Law Directive (consolidated accounts) en el Diccionario Inglés-Español de Contabilidad: Traducción de Frases y Expresiones 


\section{CONCLUSIÓN}

El objetivo de este artículo es ofrecer un conjunto de razones teóricas que justifican el empleo del término diccionario especializado y el diseño y construcción del mismo en el marco de la teoría funcional de la lexicografía. La posición teórica que hemos defendido en este trabajo la hemos ilustrado haciendo referencia a dos diccionarios de Internet pensados para satisfacer las necesidades de comunicación de los traductores profesionales que deben traducir textos de contabilidad. Uno de los diccionarios contiene los datos típicos de los diccionarios para traductores mientras que el otro ofrece varias alternativas, todas ellas pensadas para satisfacer las necesidades de un traductor experto, acostumbrado a traducir textos de especialidad aunque con lagunas conceptuales en el campo del conocimiento del diccionario.

\section{REFERENCIAS BIBLIOGRÁFICAS}

ALMIND, Richard (2005): «Designing internet dictionaries», en I. Barz, H. Bergenholtz y J. Korhonen, eds, Schreiben, Verstehen, Übersetzen, Lernen. Zu ein-und zweisprachigen Wörterbüchern mit Deutsch, Frankfurt am Main, Peter Lang, pp. 103-119.

BERGENHOLTZ, Henning (2011): «Access to and presentation of needs-adapted data in monofunctional Internet dictionaries», en Pedro A. Fuertes-Olivera y Henning Bergenholtz, eds, e-Lexicography: The Internet, Digital Initiatives and Lexicography, London \& New York, Continuum, pp. 30-53.

(2012): «Concepts for monofuctional accounting dictionaries», Terminology, 18 (2), pp. 243-263.

y Theo Bотнма (2011): «Needs-adapted Data Presentation in e-Information Tools», Lexikos, 21, pp. 53-77. Disponible en: http://lexikos.journals.ac.za/pub/article/view/37/45 (último acceso: 20 de octubre de 2012).

y Rufus Gouws (2010): «A new perspective on the access process», Hermes. Journal of Language and Communication Studies, 44, pp. 103-127. Disponible en: http://download2.hermes.asb.dk/archive/download/Hermes-44-bergenholtz\&gouws.pdf (último acceso: 20 de octubre de 2012).

y Sven TARP, eds. (1995): Manual of Specialised Lexicography. The preparation of specialised dictionaries, Amsterdam-Philadelphia, John Benjamins.

- y Sven TARP (2002): «Die moderne lexikographische Funktionslehre. Diskussionsbeitrag zu neuen und alten Paradigmen, die Wörterbücher als Gebrauchsgegenstände verstehen», Lexicographica, 18, pp. 253-263.

y Sven TARP (2003): «Two opposing theories: On H.E. Wiegand's recent discovery of lexicographic functions», Hermes. Journal of Linguistics, 31, pp. 171-196.

y Sven TARP (2004): «The concept of dictionary usage», Nordic Journal of English Studies, 3, pp. 23-36.

-, Theo BothMA y Rufus Gouws (2011): «A model for integrated dictionaries of fixed expressions», en Iztok Kosem y Karmen Kosem, eds., Electronic Lexicography in the $21^{\text {st }}$ century. New Applications for New Users. Proceedings of eLex 2011, Bled, 10- 
12 November 2011, Bled, Institute for Applied Slovene Studies, pp. 34-42. Disponible en: http://wwwtrojina.si/elex2011 (última consulta: 20 de octubre de 2012).

BотнмA, Theo J. (2011): «Filtering and adapting data and information in an online environment in response to user needs»), en Pedro A. Fuertes-Olivera y Henning Bergenholtz, eds., e-Lexicography: The Internet, Digital Initiatives and Lexicography, London \& New York, Continuum, pp. 71-102.

FATA, Ildikó (2010): «The bilingual specialised translation dictionary for learners», en Pedro A. Fuertes-Olivera, ed., Specialised Dictionaries for Learners, Berlin-New York, De Gruyter, pp. 83-103.

FeliU, Judit, Jorge ViVALDI y M. Teresa CABRÉ (2002): «Towards an Ontology for a Human Genome Knowledge Base», en LREC2002. Third International Conference on Language Resources and Evaluation. Proceedings, pp. 1885-1990. Disponible en: http://www.upf.edu/pdi/dtf/teresa.cabre/docums/ca02vi.pdf (consulta: octubre de 2012).

FuERTES-OLIVERA, Pedro A. (2009a): «Systematic introductions in specialised dictionaries: Some proposals in relation with the ACCOUNTING DiCTIONARIES», en Sandro Nielsen y Sven Tarp, eds., Lexicography in the $21^{\text {st }}$ Century. In Honour of Henning Bergenholtz, Amsterdam-Philadelphia, John Benjamins, pp. 161-178.

(2009b): «The Function theory of lexicography and electronic dictionaries: WIKTIONARY as a Prototype of Collective Multiple-Language Internet Dictionary», en $\mathrm{H}$. Bergenholtz, S. Nielsen y S. Tarp, eds., Lexicography at a Crossroads: Dictionaries and Encyclopedias Today, Lexicographica Tools Tomorrow, Bern-Berlin-BruxellesFrankfurt am Main-New York-Oxford-Wien, Peter Lang, pp. 99-134. , ed. (2010): Specialised Dictionaries for Learners, Berlin-New York, De Gruyter. (2011): «Equivalent Selection in Specialized e-Lexicography: A Case Study with Spanish Accounting Terms», Lexikos, 21, pp. 95-119.

(2012a): «Lexicography and the Internet as a (Re-)source», Lexicographica, 28, pp. $49-70$.

(2012b): «On the Usability of Free Internet Dictionaries for Teaching and Learning Business English», en Sylviane Grander y M. Paquot, eds., Electronic Lexicography, Oxford, Oxford University Press, pp. 392-417.

y Henning Bergenholtz, eds., (2011): e-Lexicography: The Internet, Digital Initiatives and Lexicography, London-New York, Continuum.

y Sandro NIELSEN (2011): «The dynamics of terms in accounting: what the construction of the accounting dictionaries reveals about metaphorical terms in culturebound subject fields», en Rita Temmerman y M. Van Campenhoudt, eds., The Dynamics of Terms in Specialized Communication. An Interdisciplinary Perspective. Special Issue of Terminology. International Journal of Applied Issues in Specialized Communication, 17, 1, pp. 157-180.

y Sandro NIELSEN (2012): «Online Dictionaries for Assisting Translators of LSP Texts: The Accounting Dictionaries», International Journal of Lexicography, 25, 2, pp. 191-215.

y Sven TARP (2008): «La teoría funcional de la lexicografía y sus consecuencias para los diccionarios de economía del español», Revista de Lexicografía, XIV, pp. 89109.

y Sven TARP (2011): «Lexicography for the Third Millennium: Cognitiveoriented Specialised Dictionaries for Learners», Ibérica, 21, pp. 141-162. 
Henning Bergenholtz, Sandro Nielsen, Pablo Gordo Gómez, Lise Mourier, Marta Niño Amo, Ángel de los Ríos Rodicio, Ángeles Sastre Ruano, Sven TARP, Marisol VelasCo SACRISTÁN (2012 $)$ : Diccionario Inglés-Español de Contabilidad: Traducción, Base de Datos y Diseño: Richard Almind y Jesper Skovgård Nielsen, Odense, Lemma.com. http://lemma.com/dictionary/special/center-forleksikografi/accounting/

- Henning Bergenholtz, Sandro Nielsen, Pablo Gordo Gómez, Lise Mourier, Marta Niño Amo, Ángel de los Ríos Rodicio, Ángeles Sastre Ruano, Sven TARP, Marisol Velasco SACRISTÁn (2012b): Diccionario Inglés-Español de Contabilidad: Traducción de Frases y Expresiones, Base de Datos y Diseño: Richard Almind y Jesper Skovgård Nielsen, Odense, Lemma.com. http://lemma.com/dictionary/special/center-for-leksikografi/accounting/

GenOMA: Banc de Coneixement sobre el Genoma Humà. http://genoma.iula.upf.edu:8080/genoma/index.jsp (consulta: octubre de 2012).

Gouws, Rufus H. (2011): «Learning, unlearning and innovation in the planning of electronic dictionaries», en Pedro A. Fuertes-Olivera, ed., Specialised Dictionaries for Learners, Berlin-New York, De Gruyter, pp. 17-29.

HEID, Ulrich y Anita GoJUN (2012): «Term candidate extraction for terminography and CAT: an overview of TTC», en 15th Euralex International Congress, August, 7-10, 2012, Oslo. Disponible en http://www.ttc-project.eu/images/stories/TTC_EURALEX_2012.pdf (consulta: octubre de 2012).

IATE (InterActive Terminology for Europe): http://iate.europa.eu/iatediff/switchLang.do? success $=$ mainPage\&lang $=$ es.

Kaufmann, Uwe, Henning Bergenholtz, en colaboración con B. Stummann, Sven Tarp, L. de la Rosa Marabet, G. la SERra Miranda y N. la Serna Torres (1998): Gene Technology Encyclopedic Dictionary, Toronto, Lugus.

Kageura, Kyo y Marie-Claude L'Homme (2008): «Reflections on fifteen years of research and development in terminology», Terminology, 14, 2, pp. 153-157.

KWARY, Deny Arnos (2011): «A hybrid method for determining technical vocabulary», System, 39, pp. 175-185.

(2012): «Adaptive hypermedia and user-oriented data for online dictionaries: A case study on an English dictionary of finance for Indonesian students», International Journal of Lexicography, 25, 1, pp. 30-49.

LEROYER, Patrick (2011): «Change of paradigm: From linguistics to information science and from dictionaries to lexicographic information tools», en Pedro A. Fuertes-Olivera y Henning Bergenholtz, eds., e-Lexicography: The Internet, Digital Initiatives and Lexicography, London-New York, Continuum, pp. 121-140.

NielSEN, Sandro (2008): «The effects of lexicographical information costs on dictionary making and use», Lexikos, 18, pp. 170-189.

y Richard ALMIND (2011): «From data to dictionary», en Pedro A. FuertesOlivera y Henning Bergenholtz, eds., e-Lexicography: The Internet, Digital Initiatives and Lexicography, London-New York, Continuum, pp. 141-167.

TARP, Sven (2002): «Translation dictionaries and bilingual dictionaries. Two different concepts», Journal of Translation Studies, 7, pp. 59-84.

(2008): Lexicography in the Borderland between Knowledge and NonKnowledge. General Lexicographical Theory with Particular Focus on Learner's Lexicography, Tübingen, Niemeyer. 
(2011): «Lexicographical and other e-tools for consultation purposes: Towards the individualization of needs satisfaction», en Pedro A. Fuertes-Olivera y Henning Bergenholtz, eds., e-Lexicography: The Internet, Digital Initiatives and Lexicography, London-New York, Continuum, pp. 55-70.

(2012a): «Specialized lexicography: 20 years in slow motion», Ibérica, 24, pp. $117-128$

(2012b): «Do we need a new theory of lexicography?», Lexikos, 22, pp. 321-332. Disponible en http://lexikos.journals.ac.za/pub/article/view/1010/527 (consulta: diciembre de 2012).

VALASKI, Joselaine, Andreia MALUCELli y Sheila R. REINEHR (2012): «Ontologies application in organizational learning: A literature review», Expert Systems with Applications, 39, 8, pp. 7555-7561.

WIKIPEDIA: http://en.wikipedia.org/wiki/Main_Page.

XUE, Mei (2010): «Countable or uncountable? That is the question: lexicographic solutions for nominal countability in learners' dictionaries for production purposes», Lexikos, 20 , pp. 540-558.

(2011): Conceptualizing lexicographic principles for production-oriented English learner's dictionaries: From the perspective of Chinese learners of English, Aarhus, Aarhus University, Faculty of Business and Social Science, Department of Business Communication (Tesis Doctoral). 